\title{
Atmospheric blocking and mean biases in climate models
}

\author{
Article \\ Published Version
}

Scaife, A. A., Woollings, T., Knight, J., Martin, G. and Hinton, T. (2010) Atmospheric blocking and mean biases in climate models. Journal of Climate, 23 (23). pp. 6143-6152. ISSN 1520-0442 doi: https://doi.org/10.1175/2010JCLI3728.1 Available at https://centaur.reading.ac.uk/19311/

It is advisable to refer to the publisher's version if you intend to cite from the work. See Guidance on citing.

To link to this article DOI: http://dx.doi.org/10.1175/2010JCLI3728.1

Publisher: American Meteorological Society

All outputs in CentAUR are protected by Intellectual Property Rights law, including copyright law. Copyright and IPR is retained by the creators or other copyright holders. Terms and conditions for use of this material are defined in the End User Agreement.

\section{www.reading.ac.uk/centaur}

\section{CentAUR}

Central Archive at the University of Reading

Reading's research outputs online 


\title{
Atmospheric Blocking and Mean Biases in Climate Models
}

\author{
ADAM A. SCAIFE \\ Met Office Hadley Centre, Exeter, United Kingdom \\ TIM WOOLLINGS \\ NCAS-Climate, Department of Meteorology, University of Reading, Reading, United Kingdom \\ JefF KNIGHT, Gill MARTin, AND Tim Hinton \\ Met Office Hadley Centre, Exeter, United Kingdom
}

(Manuscript received 15 March 2010, in final form 6 August 2010)

\begin{abstract}
Models often underestimate blocking in the Atlantic and Pacific basins and this can lead to errors in both weather and climate predictions. Horizontal resolution is often cited as the main culprit for blocking errors due to poorly resolved small-scale variability, the upscale effects of which help to maintain blocks. Although these processes are important for blocking, the authors show that much of the blocking error diagnosed using common methods of analysis and current climate models is directly attributable to the climatological bias of the model. This explains a large proportion of diagnosed blocking error in models used in the recent Intergovernmental Panel for Climate Change report. Furthermore, greatly improved statistics are obtained by diagnosing blocking using climate model data corrected to account for mean model biases. To the extent that mean biases may be corrected in low-resolution models, this suggests that such models may be able to generate greatly improved levels of atmospheric blocking.
\end{abstract}

\section{Introduction}

A number of different indices have been proposed and used to diagnose atmospheric blocking (e.g., Rex 1950; Lejenäs and Økland 1983; Tibaldi and Molteni 1990; Pelly and Hoskins 2003; Berrisford et al. 2007). By applying these indices to numerical models it has now become well established that these models underestimate blocking frequency (e.g., D'Andrea et al. 1998). Furthermore, this result is largely insensitive to the exact choice of blocking index (e.g., Doblas-Reyes et al. 1998) and the poor representation of atmospheric blocking in numerical models is now a longstanding problem.

Previous studies have identified "up-scale" feedbacks whereby small-scale atmospheric eddies help to maintain large-scale blocking structures. These structures are to some degree self-maintaining (e.g., Shutts 1986; Lau 1988; Kug and Jin 2009) and have been demonstrated to

Corresponding author address: Adam Scaife, UK Met Office Hadley Centre, FitzRoy Road, Exeter EX1 3PB, United Kingdom. E-mail: adam.scaife@metoffice.gov.uk "harvest" small-scale eddies with similar vorticity to provide the necessary positive feedback on large-scale flow (Ren et al. 2009). Given the role of small-scale eddies, it is likely that limited horizontal resolution in current climate models contributes to their lack of blocking. Indeed, recent studies with a very high horizontal resolution model report a significant increase in blocking frequency with horizontal resolution (Matsueda et al. 2009).

Other studies have suggested that in addition to resolution effects, the mean state error in climate models could also contribute to errors in blocking frequency. Kaas and Branstator (1993), Doblas-Reyes et al. (1998), Scaife and Knight (2008), Hinton et al. (2009), and Woollings et al. (2010) all reported sensitivity of blocking frequency to the climatological mean state in their models and in some cases (Scaife and Knight 2008) this was a dominant factor in explaining large differences in blocking frequency between two different models. This is perhaps not surprising given the importance of the mean flow in determining preferred regions of blocking in the real atmosphere (Masato et al. 2009). Here we investigate 
a) DJF BIAS

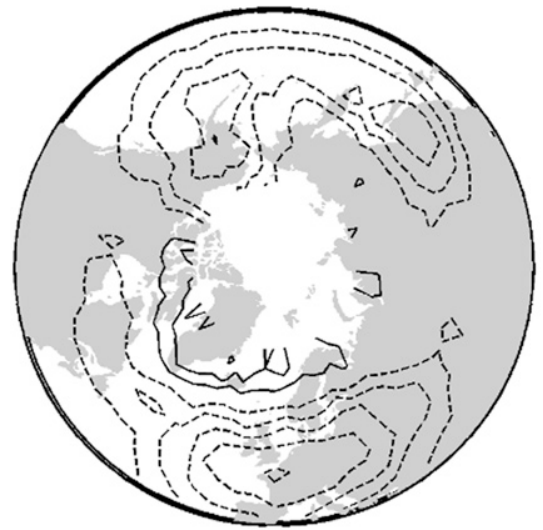

d) JJA BIAS

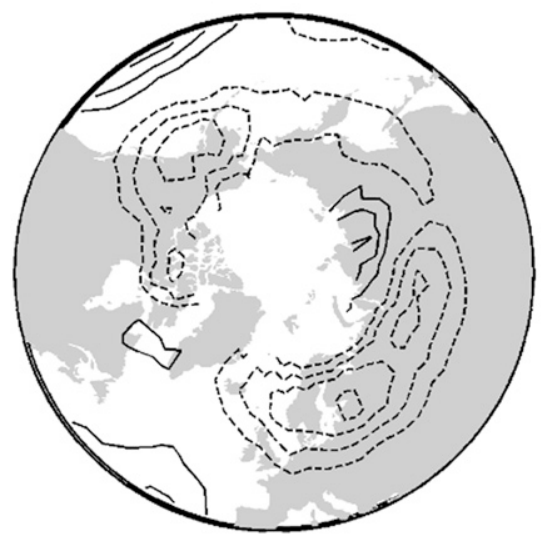

b) DJF CORRECTED

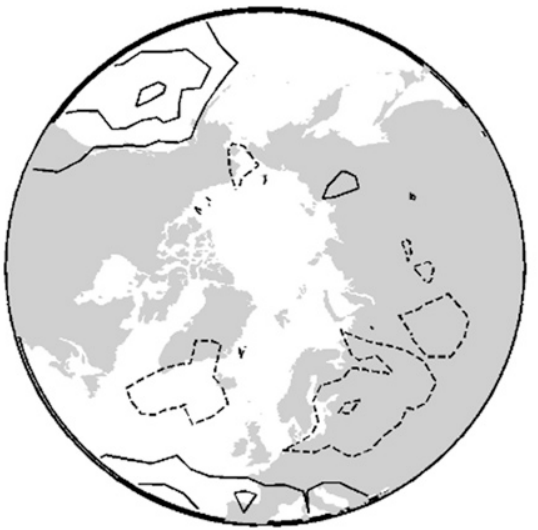

e) JJA CORRECTED

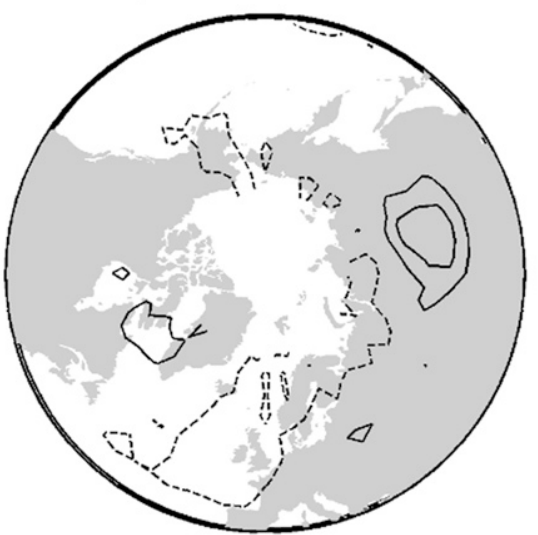

c) DJF CLIMATE

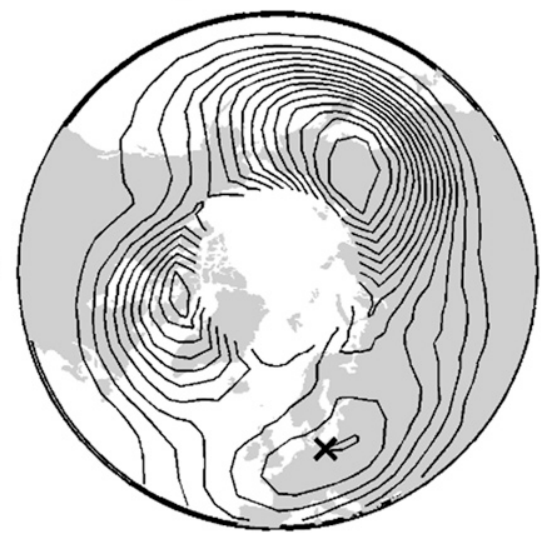

f) JJA CLIMATE

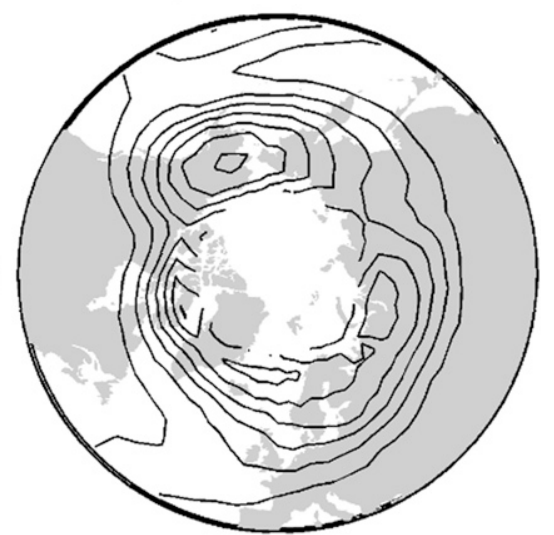

FIG. 1. (top) DJF; (bottom) JJA. (a),(b),(d),(e) Difference in blocking episode frequency in HadGAM when compared to ERA-40: (a),(d) using the raw model output and (b),(e) with the model climatology replaced with that of ERA-40 before application of the blocking index. The contour interval 0.03 day $^{-1}$ with negative contours dashed and the zero contour omitted. (c),(f) Mean blocking frequency. The contour interval is $0.05 \mathrm{day}^{-1}$. In (c), the ' $\mathrm{X}$ ' marks the location of the grid point nearest to the blocking maximum used to calculate the PDF of blocking index shown in Fig. 2.

this sensitivity to the climatological mean state in more detail and expand the results to a wide range of models.

It could be argued that the separation of time mean errors from blocking frequency errors in models is difficult; after all, insufficient blocking in the models could itself be causing the error in the mean state (Tibaldi and Molteni 1990). Errors in the modeled blocking frequency could be due to errors in the climate mean, errors in the time varying part, or both. To address this we split the model $(M)$ and observed $(O)$ atmospheric state into steady $(\bar{M}, \bar{O})$ and time-varying $\left(M^{\prime}, O^{\prime}\right)$ parts. Since commonly used blocking indices count the frequency of reversal of the meridional gradient of, for example, geopotential height (Tibaldi and Molteni 1990) or potential temperature (Pelly and Hoskins 2003), we consider meridional gradients:

$$
\begin{gathered}
\frac{\partial M(t)}{\partial y}=\frac{\partial \bar{M}}{\partial y}+\frac{\partial M^{\prime}(t)}{\partial y}, \\
\frac{\partial O(t)}{\partial y}=\frac{\partial \bar{O}}{\partial y}+\frac{\partial O^{\prime}(t)}{\partial y} .
\end{gathered}
$$

We can now test whether errors in blocking arise from the time mean by exchanging the climatological mean in the model $(\partial \bar{M} / \partial y)$ for the climatological mean in the observations $(\partial \bar{O} / \partial y)$ and recalculating the blocking statistic:

$$
\frac{\partial M^{*}(t)}{\partial y}=\frac{\partial \bar{O}}{\partial y}+\frac{\partial M^{\prime}(t)}{\partial y}
$$

If this procedure removes the error in blocking and the model variability $\left(\partial M^{\prime}(t) / \partial y\right)$ is realistic, then the 

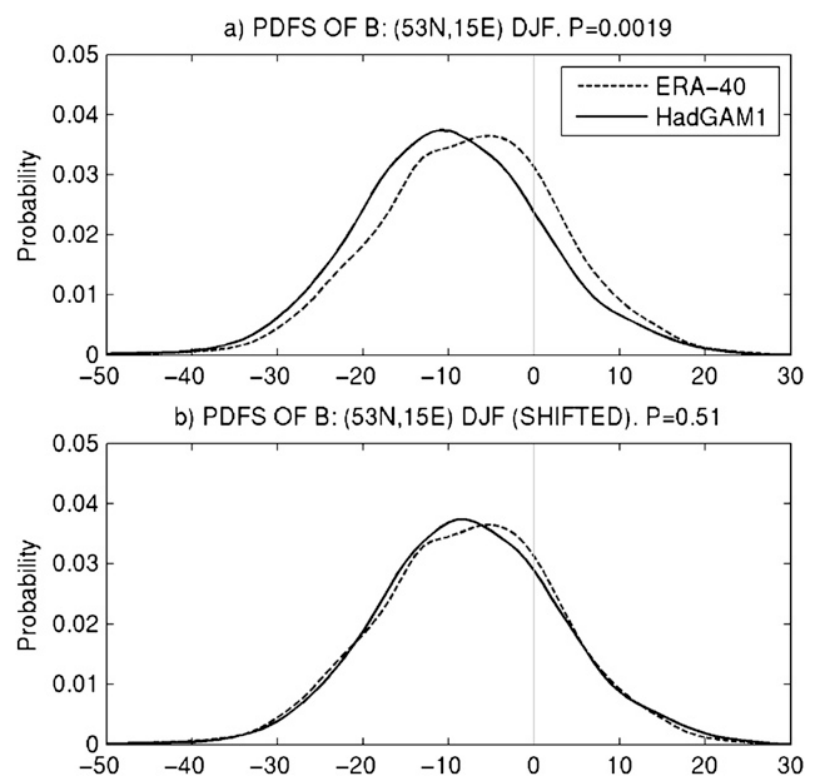

FIG. 2. PDFs of blocking index, the meridional contrast in theta (PV2), for the gridpoint marked ' $\mathrm{X}$ ' nearest the blocking maximum in the previous figure, (a) using the raw model output and (b) with the model climatology replaced with that of ERA-40. The $p$ values give the probability that the two samples are drawn from the same underlying distribution using a two-sample Kolmogorov-Smirnov test and assuming an independent sample every 7 days.

blocking error must arise in the climatological mean field of the model. Of course, transient components of the circulation could still be driving errors in the mean state, but the above breakdown into mean and variability is nonetheless valid and in this paper we examine both the mean climate error and the distribution of variability to demonstrate that much of the blocking error in current climate models lies in the mean state of these models.

\section{Blocking errors in a single climate model}

We first diagnose blocking in the atmospheric component of the Hadley Centre Global Environmental Model (HadGEM) (Martin et al. 2006; Ringer et al. 2006). We use the two-dimensional blocking index of Berrisford et al. (2007) applied to the Northern Hemisphere (Fig. 1). This index searches daily data for a reversal of the usual (negative) meridional gradient of potential temperature $(\theta)$ on the surface where potential vorticity is equal to 2 PVU $\left(1 \mathrm{PVU}=1 \times 10^{6} \mathrm{~K} \mathrm{~m}^{2} \mathrm{~kg}^{-1} \mathrm{~s}^{-1}\right)$. The difference in $\theta$ averaged over boxes of $15^{\circ}$ latitude north and south of the point in question is calculated. When this is larger than zero there could be a block-we then apply time and space scales that it must pass before it can be called a blocking episode. This ensures that episodes are stationary and persistent, lasting at least 5 days. Episodes are identified using data from the whole year; then only December-February (DJF) [or June-August (JJA)] days are retained. [See Berrisford et al. (2007) for more details.]

We use a 60-level version of the Hadley Centre model with horizontal resolution $1.875^{\circ}$ longitude by $1.25^{\circ}$ latitude to simulate the period 1961-2002 by forcing with observed sea surface temperatures, sea ice cover, and increasing greenhouse gases as described by Woollings et al. (2010). Like most other climate models (e.g., D'Andrea et al. 1998), this model exhibits a large deficit in diagnosed blocking frequency. In winter (Fig. 1a) there is a deficit in blocking in both the Atlantic and Pacific storm-track regions of the Northern Hemisphere. This error is largest near the end of the storm tracks at the eastern side of each basin where blocking tends to be most frequent. A similar error occurs in summer (Fig. 1d) when the model shows insufficient blocking in both storm-track regions, although now the Atlantic error is shifted northward and eastward, consistent with the seasonal shift in the storm-track position. There are small regions of positive anomaly in both seasons but the major difference between the model and observed blocking is that the model underrepresents observed blocking by up to $60 \%$. Note that these regions coincide with the location of the North Atlantic Oscillation (NAO) and as the NAO is closely related to blocking, similar errors are also likely to be present in the absolute values of the NAO index.

As discussed in the previous section, an error in the blocking frequency could come from an error in the modeled variability, an error in the mean state of the model, or a combination of the two. Of course, more or less blocking may also affect the mean state but that does not detract from the breakdown in Eq. (1), and if the variability can be demonstrated to be accurately modeled then the error must arise in the mean state. It is difficult in practice to demonstrate that the variability in the blocking index is perfectly accurately modeled, but to test these three possibilities we examine the values of the daily blocking index (B) in the model near the maximum of Atlantic/European blocking (Fig. 2a). As explained above, blocking is normally taken to occur when the $\mathrm{B}$ index is greater than zero. The blocking frequency is related to the proportion of the area under the distribution in Fig. 2a that lies above a B value of zero (the time and space scales also have to be passed before these days can be considered part of a blocking episode). It can be seen that in the Hadley Centre Global Atmosphere Model (HadGAM1), this area is less than the area in observational analyses, confirming a deficit in blocking frequency for the model at this location and in agreement with Fig. 1a. 

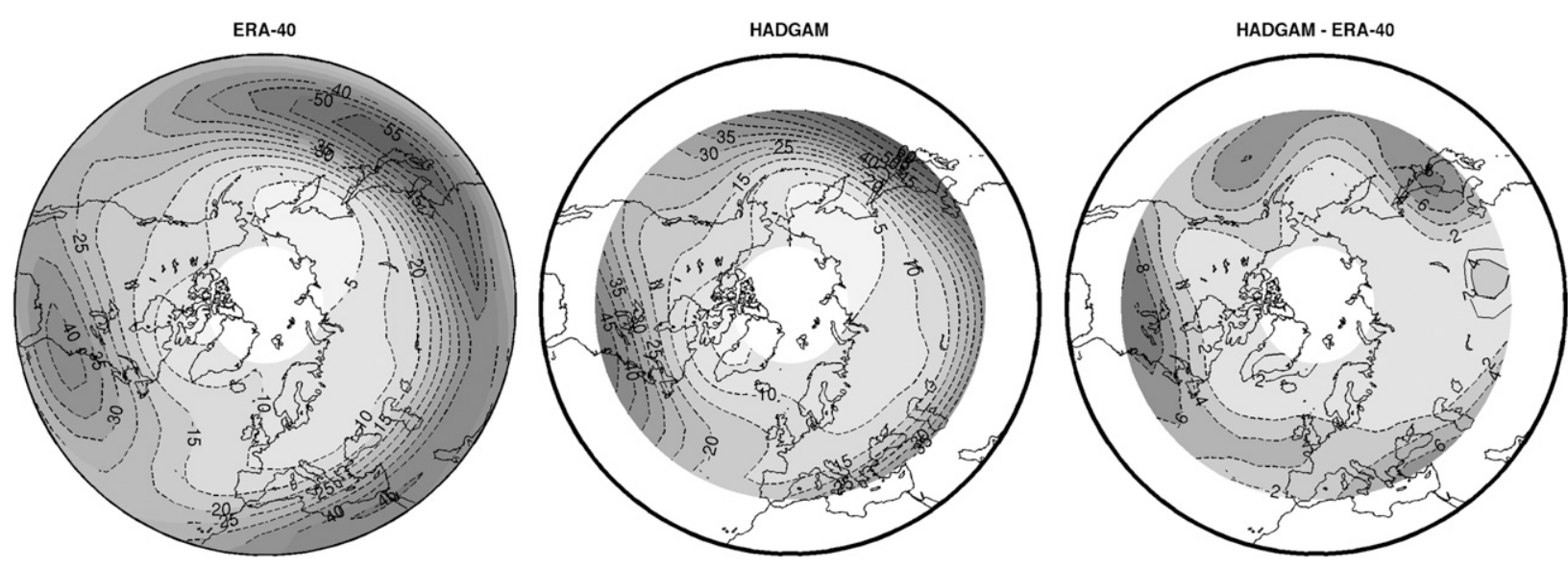

FIG. 3. Climatological mean values of the winter blocking index B (as opposed to blocking frequency) in (left) ERA-40 reanalyses and (middle) the Hadley Centre Global Atmospheric Model, and (right) the error in the model. The hemispheric scale of the model error shows that it is present at all longitudes. Units are $\mathrm{K}^{-1}$.

Closer inspection of Fig. 2 also illustrates that despite the underestimate in blocking frequency, the width of the distribution of $\mathrm{B}$ is actually very realistic. The variability in the modeled blocking index $\mathrm{B}$ is therefore accurately modeled and the major reason for the deficit in blocking frequency is simply a shift in the mean value of $\mathrm{B}$, or equivalently, the climatological gradient $(\partial \bar{M} / \partial y)$ in the model. This is supported by Fig. $2 b$ where the distribution of modeled blocking index is artificially shifted to give the same mean value as the observed index [Eq. (3)] while preserving the shape of the distribution. The two distributions are now statistically indistinguishable and it is therefore the mean state, rather than the intrinsic level of variability in the model, that is directly responsible for the lack of diagnosed blocking. Note that the mean state bias $(\partial \bar{M} / \partial y-\partial \bar{O} / \partial y)$ is also no larger in the region where European blocking is poorly represented than in other regions (Fig. 3), which is consistent with the idea that blocking itself is not the primary reason for the mean state bias.

We now return to the geographical distribution of blocking in the models shown in Fig. 1. By correcting the mean state of the model at each gridpoint location and in each season and recalculating the blocking statistics, errors in diagnosed blocking frequency are greatly reduced almost everywhere (Fig. 1b). The same result holds for summer blocking (Fig. 1e). This suggests that errors in the mean state of the climate model rather than errors in the transient component of the blocking index are the dominant factor in determining errors in diagnosed blocking frequency. Note again that we fully acknowledge the role of transient fluctuations in driving the mean flow and that it could be this driving process (through wave breaking of transient eddies) rather than the fluctuations themselves that is poorly represented. However, there are many other reasons why mean biases exist in models, so our finding that correcting these mean state errors would lead to large improvements in diagnosed blocking frequency is potentially very relevant to climate model development.

\section{Generalization to other climate models}

We now generalize this result to a number of other state-of-the-art climate models. Simulation data are from the World Climate Research Programme (WCRP) Working Group on Coupled Modeling (WGCM) Coupled Model Intercomparison Project phase 3 (CMIP3) multimodel dataset, which was used in the Intergovernmental Panel on Climate Change (IPCC) Fourth Assessment Report (AR4) (Solomon et al. 2007). The data were obtained from the archive held by the Program for Climate Modeling Diagnosis and Intercomparison (PCMDI) at the Lawrence Livermore National Laboratory (LLNL). The simulations used are the preindustrial control calculations, except for the Max Planck Institute (MPI) ECHAM5 model, for which twentieth-century simulations are used because of the availability of data. In general, daily or subdaily $500-\mathrm{hPa}$ geopotential height data (the most usual variable for the calculation of blocking) are not available from the CMIP3 archive. As a result, daily mean $500-\mathrm{hPa}$ zonal wind speed is used instead. The accuracy of the geostrophic relationship in the extratropical atmosphere suggests that there should be little difference between blocking measures derived with either variable. Nevertheless, climatological blocking frequency was diagnosed from 500-hPa geopotential height and zonal wind using data from the 40-yr European 

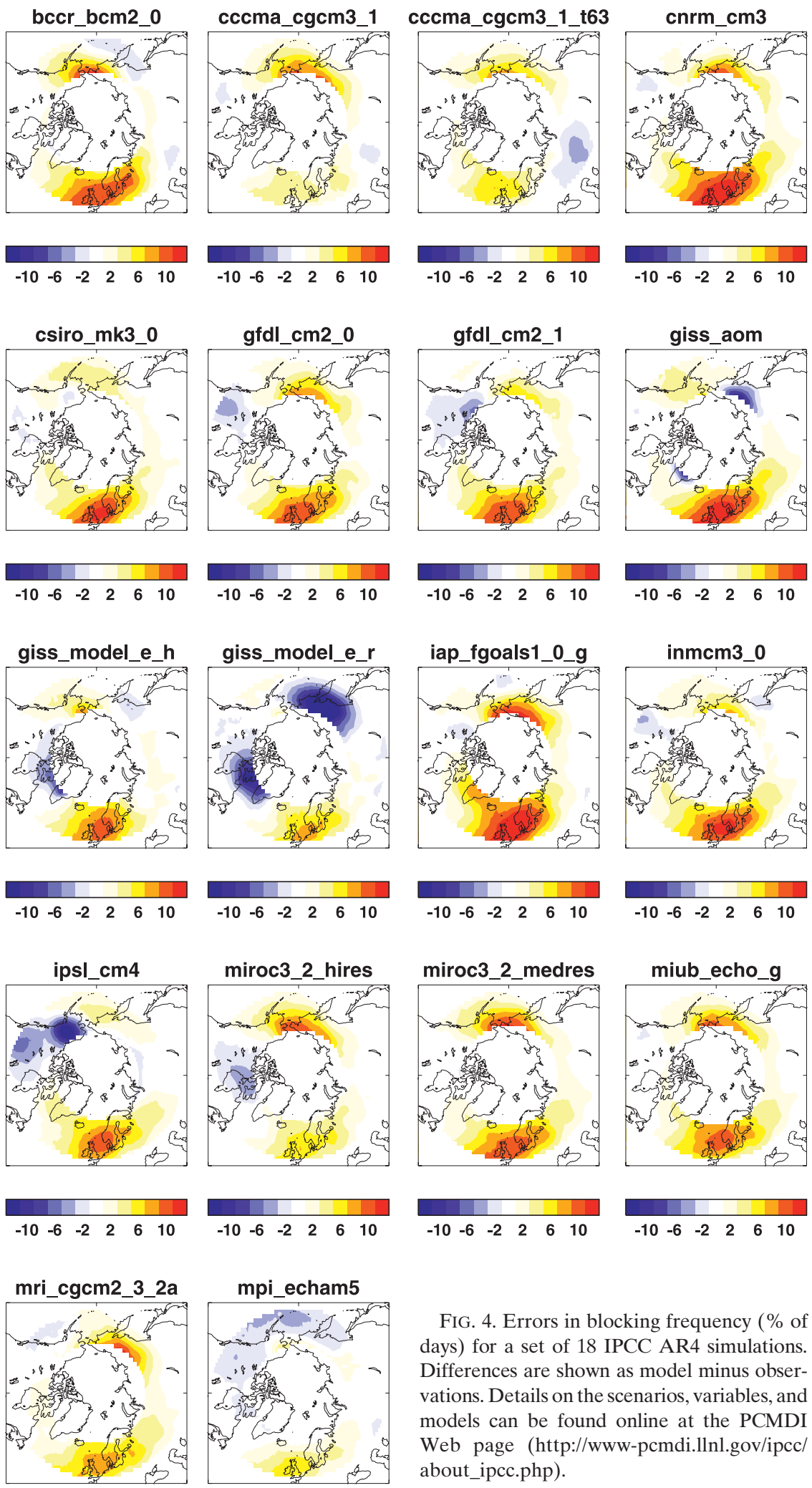

FIG. 4. Errors in blocking frequency (\% of days) for a set of 18 IPCC AR4 simulations. Differences are shown as model minus observations. Details on the scenarios, variables, and models can be found online at the PCMDI Web page (http://www-pcmdi.llnl.gov/ipcc/ about_ipcc.php). 

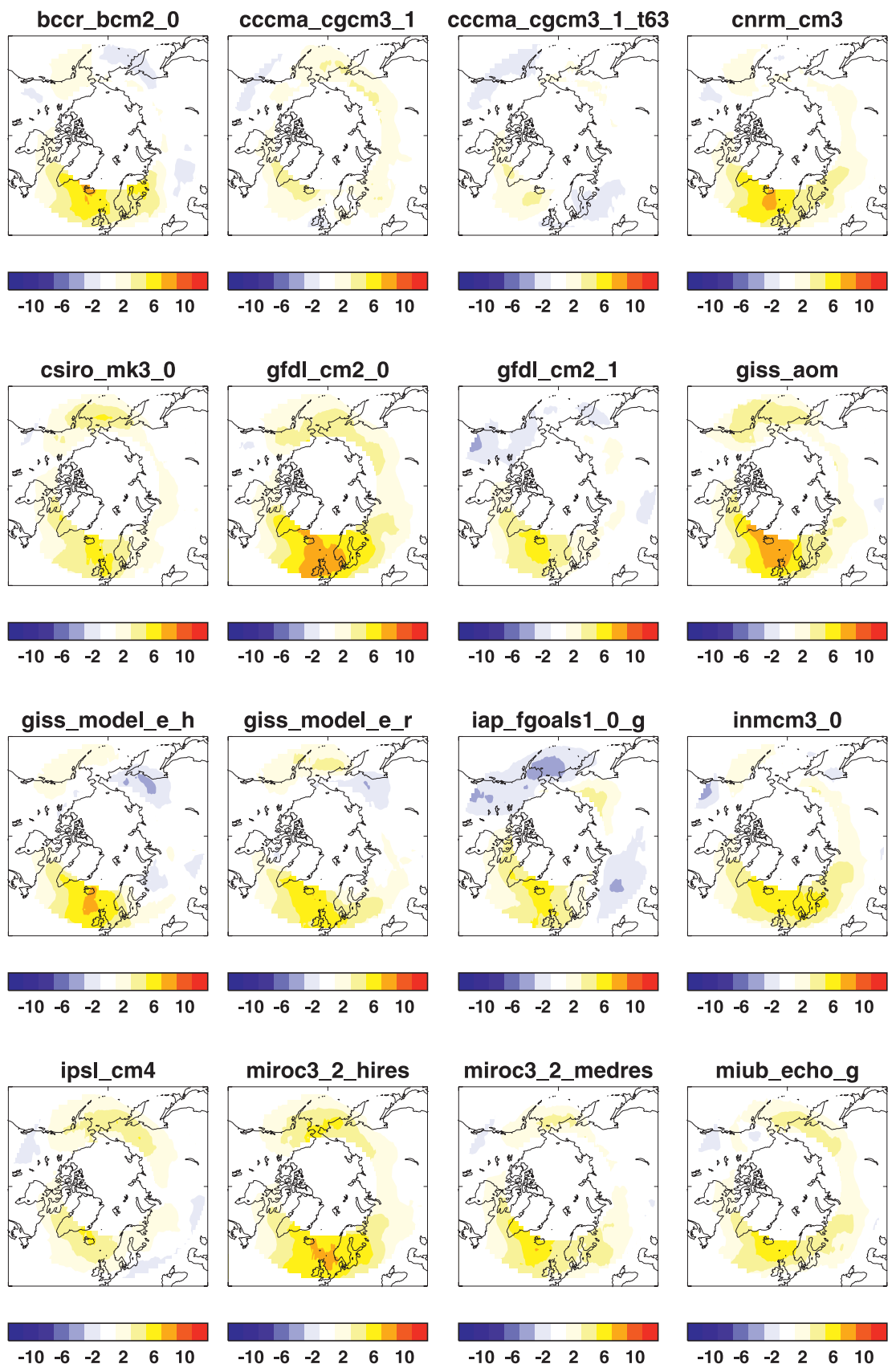

mri_cgcm2_3_2a

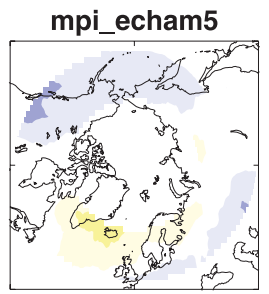

FIG. 5. Errors in blocking frequency ( $\%$ of days) for the same set of model simulations as in Fig. 3 in which the background mean state has been replaced by observed climatology. Differences are shown between the observations and modeled frequency.

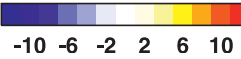

$\begin{array}{cccccc}-10 & -6 & -2 & 2 & 6 & 10\end{array}$ 
Centre for Medium-Range Weather Forecasts (ECMWF) Re-Analysis (ERA-40) for 1957-2002. These indeed showed that there are only very slight differences in the pattern and amplitude of climatological blocking when zonal wind is used in place of geopotential height. Forty years of daily data are available for each model, except for the Goddard Institute for Space Studies AtmosphereOcean Model (GISS-AOM), which has 80 years, and the twentieth-century data from MPI ECHAM5, which cover 140 years from 1860 to 2000. Daily DJF data are extracted for the analysis. The spatial pattern of climatological blocking is computed for the models by using an approach equivalent to that of Tibaldi and Molteni (1990) for use with zonal wind data. This provides the following point criteria for blocking: the mean of the product of zonal wind with the sine of the latitude must be negative (net easterly) over the $20^{\circ}$ latitude range to the south and greater than $6 \mathrm{~m} \mathrm{~s}^{-1}$ (westerly) in the $20^{\circ}$ range to the north. See the appendix for details of the calculation.

Figure 4 shows that the errors in blocking frequency in our earlier example of the HadGEM model are common to many current climate models. Almost all models underestimate blocking frequency and the main errors occur in similar geographical regions coinciding with the Atlantic and Pacific storm tracks. There are particularly large errors toward the end of the Atlantic storm track in most models. While the majority of climate models show a deficit in diagnosed blocking, there are a few cases where regional blocking is more frequent than observed, for example in the GISS or L'Institut PierreSimon Laplace (IPSL) models and a few examples where models have relatively small errors in blocking, for example in the ECHAM5 (cf. Sillmann and Croci-Maspoli 2009) and Canadian Centre for Climate Modelling and Analysis (CCCma) models.

We now perform the same test on this wide set of models as previously carried out on our single model. Figure 5 shows the blocking frequency recalculated after the mean state of each model has been corrected to that calculated from observational analyses. As with the single model example above, the majority of blocking error is removed when the mean state is corrected, suggesting that model blocking errors in general are largely (though not completely) attributable to climatological model biases. Note also that the positive regional biases in blocking frequency in the GISS and IPSL models and the relatively small errors in ECHAM5 and CCCma are equally well corrected by shifting the mean state. This suggest that our results are, to a large degree, model independent and that correcting mean state errors (or more specifically mean gradient errors) would greatly reduce diagnosed blocking errors in the current generation of climate models.

\section{Improved blocking through model development}

Atlantic-European blocking from two versions of the Hadley Centre Global Environmental Model (Martin et al. 2006; Ringer et al. 2006) is used as an example of how model development can improve simulated blocking frequency. The early version of this model shows a strong bias toward low geopotential height in the far northern Atlantic and high values in the subtropics. This corresponds to a strong westerly bias in the model and the familiar lack of Atlantic blocking (Fig. 6, lower panel, dashed curve). In a more recent version of the model some of this bias has been alleviated (the exact changes to the model are irrelevant to our study here but note that the resolution is the same). The resulting model has a much smaller bias in the meridional gradient of geopotential height and, as expected from our analyses above, the diagnosed blocking frequency is significantly increased. Finally, to confirm that this increase is indeed due to the change in the mean model state, we repeated the procedure in Eq. (3) but now replaced the mean model state in the old model with that from the new model. Figure 6 verifies that the change in blocking frequency is reproduced and changes in these common measures of blocking can be achieved by improving the mean state of the model without altering model resolution.

\section{Conclusions}

Underestimation of blocking frequency is a longstanding problem for numerical models of the atmosphere. It also occurs in current-generation weather forecast models as well as in lower-resolution climate models. In this study we have demonstrated that one key source of error in blocking statistics is mean model bias. This affects diagnosed blocking frequency by biasing the meridional gradient in the models; because blocking is often diagnosed as a reversal of this mean gradient, then a strong mean gradient leads to reduced blocking even if the model contains realistic levels of fluctuations from day to day.

By extending this result to a suite of state-of-the-art models used in the recent Fourth Assessment Report of the IPCC (Solomon et al. 2007), we showed that this result is model independent and that models in general contain significant blocking errors due to errors in their mean state. In the vast majority of cases this makes a large contribution to the deficit of blocking frequency in models, and in a few cases it produces a surfeit of blocking occurrences. In both cases, the errors are much reduced if the mean state is corrected.

This source of error is complementary to any errors in blocking due to other factors such as external forcing 
(a) geopotential height at $500.0 \mathrm{hPa}$

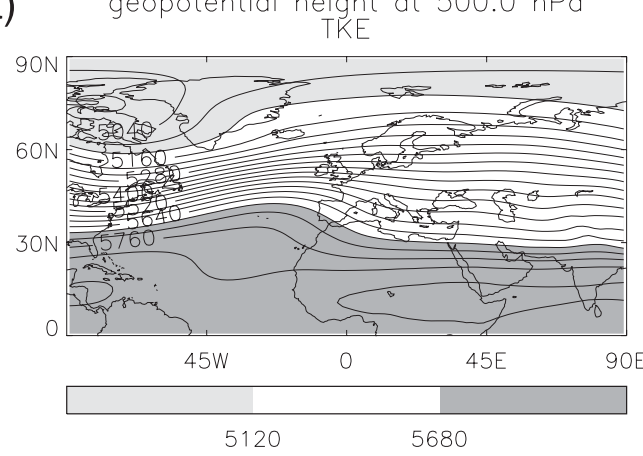

geopotential height at $500.0 \mathrm{hPa}$ CTL - ERA40

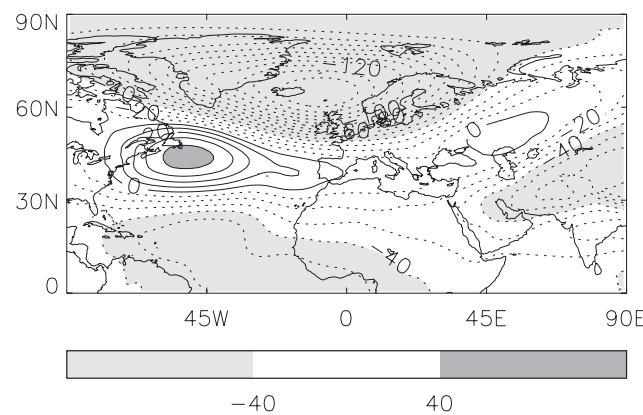

geopotential height at $500.0 \mathrm{hPa}$ TKE - CTL

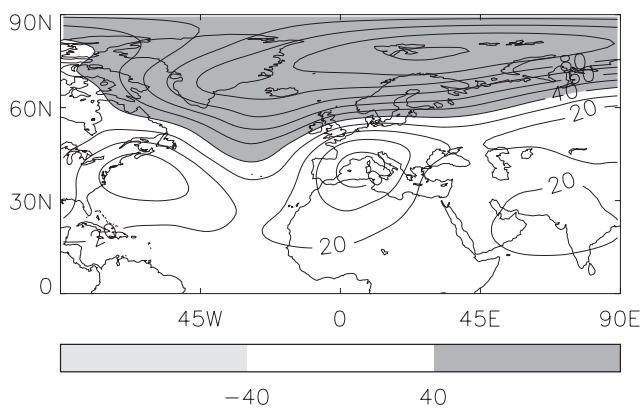

geopotential height at $500.0 \mathrm{hPa}$ TKE - ERA40

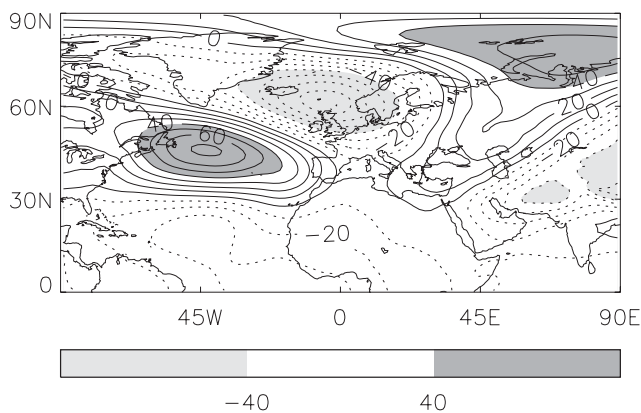

(b)

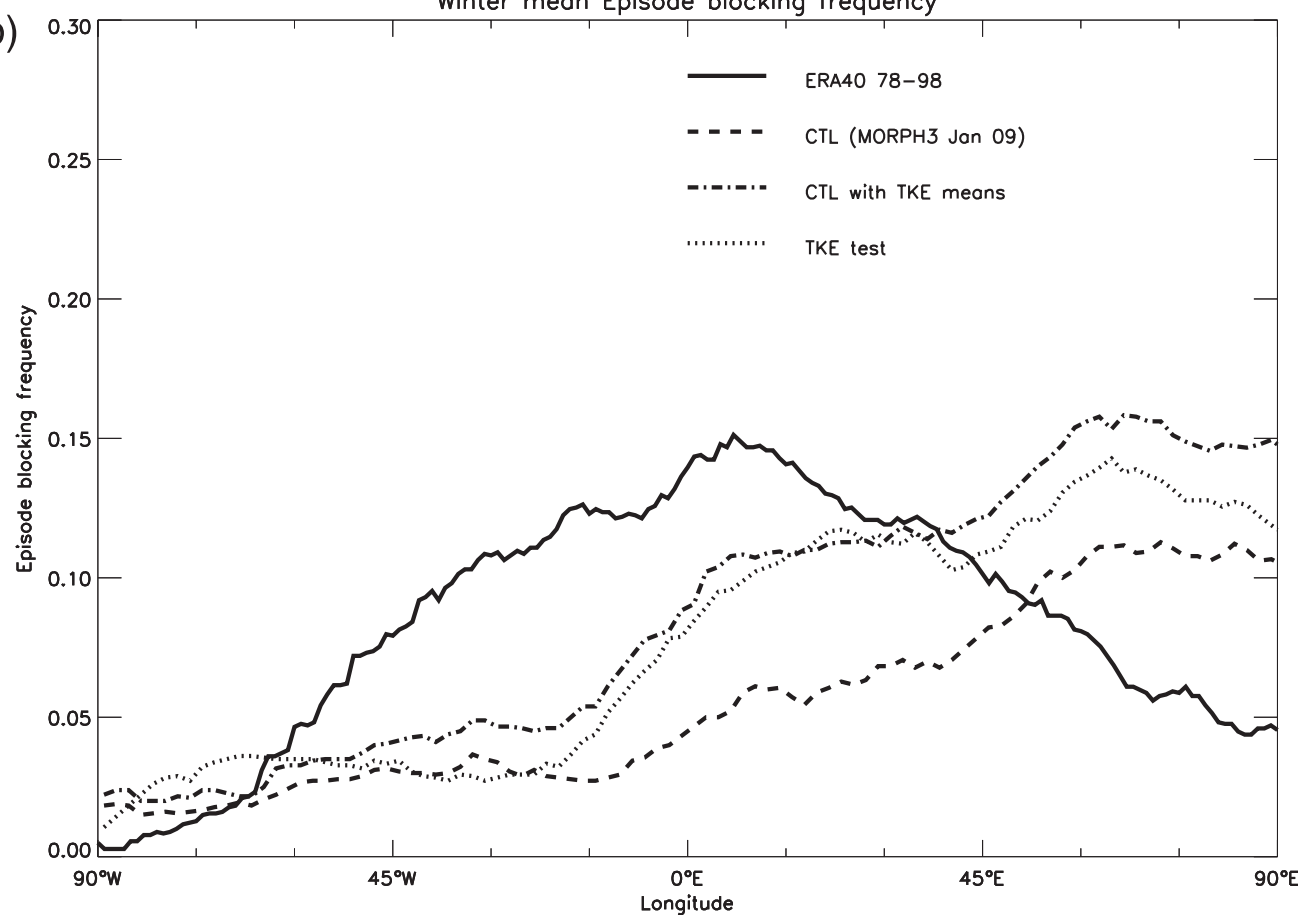

FIG. 6. Reduction in blocking error due to model mean climate improvement. (top) The mean 500-hPa geopotential height in winter (DJF) (left) in a new version of the Hadley Centre climate model (TKE)and (right) the difference from a previous version of the model (TKE - CTL). (middle) Errors relative to ERA-40 reanalyses for the (left) previous and (right) new model. The large overestimate of the latitudinal gradient of geopotential height has been reduced in the new model. The resulting blocking frequency is plotted in the bottom panel (dotted curve) along with the result of simply exchanging the mean states between the models (dashed-dotted curve) and the original model (dashed curve). The similarity of the dotted and dashed-dotted curve suggests that most of the increase in blocking arises from an improved mean state. The solid line shows observed frequency. 
(e.g., Barriopedro et al. 2008) or limited horizontal resolution in climate models. Clear demonstrations of upscale reinforcement of large blocks by small transient eddies (e.g., Shutts 1986) suggest that horizontal resolution could also be important in correcting model blocking errors. Given the role of small-scale eddies, it is also not surprising that very high-horizontal-resolution models also produce an increase in blocking (Matsueda et al. 2009). However, it would be interesting to further analyze the role of horizontal resolution in this respect-in particular, to distinguish the resolution impact on the mean state from its impact on the processes that generate blocks in the models. It seems that the changes in blocking frequency due to increased resolution found by Matsueda et al. (2009; see their Fig. 2) are actually also consistent with the change in the mean state in that model in both the Pacific and Atlantic basins.

Of course, we acknowledge the role of transient fluctuations in driving the mean flow and it could be this driving process (through wave breaking of transient eddies) rather than the transients themselves that is poorly represented. However, as stated above, there are many other reasons why mean biases exist in models, so it is important to reemphasize the importance of these mean state errors for simulating blocking frequency.

To summarize our results, commonly applied blocking statistics based on absolute measures (such as the reversal of geopotential height or PV gradients) show large errors in current climate models, but these are directly attributable to a large degree to errors in the main state rather than errors in variability. Statistics based on other measures such as those employed by Schwierz et al. (2004) or Kaas and Branstator (1993) would be better to examine the remaining blocking errors that are independent of mean state errors.

Finally, a consequence of our results is that while we acknowledge the likely importance of high horizontal resolution for simulating accurate blocking, reducing local mean biases in low-resolution climate models by improving parameterizations (e.g., Palmer et al. 1986) should lead to large improvements in simulated blocking statistics.

Acknowledgments. This research was supported by the Joint DECC and DEFRA Integrated Climate Programme, DECC/DEFRA (GA01101). We acknowledge the modeling groups, the Program for Climate Model Diagnosis and Intercomparison (PCMDI), and the WCRP's Working Group on Coupled Modelling (WGCM) for their roles in making available the WCRP CMIP3 multimodel dataset. Support of this dataset is provided by the Office of Science, U.S. Department of Energy.

\section{APPENDIX}

\section{Zonal Wind-Based Interpretation of the Tibaldi and Molteni Blocking Index}

The index defined by Tibaldi and Molteni (1990) is used here with only the central latitude test but is applied to all grid points between $50^{\circ}$ and $70^{\circ} \mathrm{N}$. The test is applied to daily zonal wind fields from each model using the geostrophic relationship and integrating between latitudes $\phi_{1}$ and $\phi_{2}$ :

$$
\Delta Z=-\frac{2 a \Omega}{g} \int_{\phi_{1}}^{\phi_{2}} u \sin \phi d \phi
$$

where all quantities have their usual meaning. For model gridpoint data this becomes

$$
\Delta Z=-\frac{2 a \Omega}{g} \frac{\left(\phi_{2}-\phi_{1}\right)}{n} \sum_{i=1}^{n} u_{i} \sin \phi_{i}
$$

with $n$ grid points between $\phi_{1}$ and $\phi_{2}$ and using a $20^{\circ}$ interval. Tibaldi and Molteni's first criterion $(\Delta Z>0$; reversal of the climatological height gradient) applied to zonal wind then requires net easterly winds:

$$
\sum_{i=1}^{n} u_{i} \sin \phi_{i}<0
$$

The second criterion is $\Delta Z<-200 \mathrm{~m}$ for a $20^{\circ}$ interval, implying

$$
\frac{1}{n} \sum_{i=1}^{n} u_{i} \sin \phi_{i}>\frac{200}{\left(\phi_{2}-\phi_{1}\right)}\left(\frac{g}{2 a \Omega}\right) .
$$

Blocking is identified when (A3) and (A4) are satisfied.

\section{REFERENCES}

Barriopedro, D., R. García-Herrera, and R. Huth, 2008: Solar modulation of Northern Hemisphere winter blocking. J. Geophys. Res., 113, D14118, doi:10.1029/2008JD009789.

Berrisford, P., B. J. Hoskins, and E. Tyrlis, 2007: Blocking and Rossby wave breaking on the dynamical tropopause in the Southern Hemisphere. J. Atmos. Sci., 64, 2881-2898.

D'Andrea, F., and Coauthors, 1998: Northern Hemisphere atmospheric blocking as simulated by 15 atmospheric general circulation models in the period 1979-1998. Climate Dyn., 14, 385-407.

Doblas-Reyes, F. J., M. Déqué, F. Valero, and D. B. Stephenson, 1998: North Atlantic wintertime intraseasonal variability and its sensitivity to GCM horizontal resolution. Tellus, 50A, 573-595.

Hinton, T. J., B. J. Hoskins, and G. M. Martin, 2009: The influence of tropical sea-surface temperatures and precipitation on North Pacific atmospheric blocking. Climate Dyn., 33, 549-563. 
Kaas, E., and G. Branstator, 1993: The relationship between a zonal index and blocking activity. J. Atmos. Sci., 50, 30613077.

Kug, J.-S., and F.-F. Jin, 2009: Left-hand rule for synoptic eddy feedback on low-frequency flow. Geophys. Res. Lett., 36, L05709, doi:10.1029/2008GL036435.

Lau, N.-C., 1988: Variability of the observed midlatitude storm tracks in relation to low-frequency changes in the circulation pattern. J. Atmos. Sci., 45, 2718-2743.

Lejenäs, H., and H. Økland, 1983: Characteristics of Northern Hemisphere blocking as determined from a long time series of observational data. Tellus, 35A, 350-362.

Martin, G. M., M. A. Ringer, V. D. Pope, A. Jones, C. Dearden, and T. J. Hinton, 2006: The physical properties of the atmosphere in the new Hadley Centre Global Environmental Model (HadGEM1). Part I: Model description and global climatology. J. Climate, 19, 1274-1301.

Masato, G., B. Hoskins, and T. Woollings, 2009: Can the frequency of blocking be described by a red noise process? J. Atmos. Sci., 66, 2143-2149.

Matsueda, M., R. Mizuta, and S. Kusunoki, 2009: Future change in wintertime atmospheric blocking simulated using a $20-\mathrm{km}$ mesh atmospheric global circulation model. J. Geophys. Res., 114, D12114, doi:10.1029/2009JD011919.

Palmer, T. N., G. J. Shutts, and R. Swinbank, 1986: Alleviation of a westerly bias in general circulation and numerical weather prediction models through an orographic gravity wave drag parametrization. Quart. J. Roy. Meteor. Soc., 112, 1001-1039.

Pelly, J., and B. Hoskins, 2003: A new perspective on blocking. J. Atmos. Sci., 60, 743-755.

Ren, H.-L., F.-F. Jin, J.-S. Kug, J.-X. Zhao, and J. Park, 2009: A kinematic mechanism for positive feedback between synoptic eddies and NAO. Geophys. Res. Lett., 36, L11709, doi:10.1029/ 2009 GL037294.

Rex, D. F., 1950: Blocking action in the middle troposphere and its effect upon regional climate. 1. An aerological study of blocking action. Tellus, 2, 196-211.

Ringer, M. A., and Coauthors, 2006: The physical properties of the atmosphere in the New Hadley Centre Global Environmental Model (HadGEM1). Part II: Aspects of variability and regional climate. J. Climate, 19, 1302-1326.

Scaife, A. A., and J. R. Knight, 2008: Ensemble simulations of the cold European winter of 2005/6. Quart. J. Roy. Meteor. Soc., 134, 1647-1659.

Schwierz, C., M. Croci-Maspoli, and H. C. Davies, 2004: Perspicacious indicators of atmospheric blocking. Geophys. Res. Lett., 31, L06125, doi:10.1029/2003GL019341.

Shutts, G. J., 1986: A case study of eddy forcing during an Atlantic blocking episode. Advances in Geophysics, Vol. 29, Academic Press, 135-162.

Sillmann, J., and M. Croci-Maspoli, 2009: Present and future atmospheric blocking and its impact on European mean and extreme climate. Geophys. Res. Lett., 36, L10702, doi:10.1029/ 2009GL038259.

Solomon, S., D. Qin, M. Manning, M. Marquis, K. Averyt, M. M. B. Tignor, H. L. Miller Jr., and Z. Chen, Eds., 2007: Climate Change 2007: The Physical Science Basis. Cambridge University Press, 996 pp.

Tibaldi, S., and F. Molteni, 1990: On the operational predictability of blocking. Tellus, 42A, 343-365.

Woollings, T., A. Charlton-Perez, S. Ineson, A. G. Marshall, and G. Masato, 2010: Associations between stratospheric variability and tropospheric blocking. J. Geophys. Res., 115, D06108, doi:10.1029/2009JD012742. 